\title{
The Influence of Evolution on Dewey's Educational and Philosophical Thoughts
}

\author{
Liu Huachu
}

\begin{abstract}
Evolution has a great impact on Dewey's philosophical and educational thoughts. Many fundamental conceptions of Dewey's educational philosophy such as continuity, growth, contingency, development, and genetic methodology, could be traced back to Darwinian Evolutionary theory. Dewey reconstructs the ideas and methods of traditional philosophy based on Evolution, and introduces a lot of new scientific methods into educational theory and practices. With changing idea in his mind, Dewey thinks knowledge cannot be a fixed content divorced from experience, but skills and rules to be learnt from experience, which are gradually acquired through students' interaction with environment and nature in the learning process. In conclusion, philosophy for Dewey is a method of knowledge rather than a repository of disembodied, preexisting absolute truths.
\end{abstract}

Index Terms-Evolution, educational thought, dewey, pragmatism.

\section{INTRODUCTION}

As one of the most famous pragmatists and preeminent educational philosophers, John Dewey created his broad philosophical and educational thoughts on the basis of experimental naturalism. However, many fundamental conceptions of his educational philosophy such as continuity, growth, contingency, development, and genetic method, could be traced back to Darwinian Evolutionary theory. Encouraged by Darwin's explanations about species, Dewey reconstructs the ideas and methods of traditional philosophy. $\mathrm{He}$ also introduces a lot of new scientific methods into educational theory and practices, and uses critical intelligence to reject the traditional ways of viewing philosophical discourse. With changing idea in his mind, Dewey thinks knowledge cannot be a fixed content divorced from experiences, but skills and rules to be learnt from experiences for students, which are gradually acquired through students' interaction with environment and nature in the learning process. Therefore, philosophy for Dewey is a method of knowledge rather than a repository of disembodied absolute truths established upon a priori grounds. If there is anyone who gave Dewey great impact on his thoughts of philosophy, that person must be Darwin, although W. James and the great dialectic idealist, G. Hegel, both are Dewey's philosophical sources. As Dewey said himself, "Doubtless the greatest dissolvent in contemporary thought of old questions, the greatest precipitant of new methods, new intentions, new problems, is the one affected by the scientific revolution that found its climax in The

Manuscript received November 5, 2012; revised January 16, 2013.

Liu Huachu is with the Hainan Normal University, Haikou, Hainan 571158 China (e-mail: liuhuachu88@163.com).
Origin of Species". [1]

\section{DEWEY RECONSTRUCTED THE TRADITIONAL EMPIRICISM WITH DARWIN'S EVOLUTION}

Dewey was born in the same year as Darwin's epoch-making magnum opus, The Origin of Species, was published, so the great work seems to be a natural resource for Dewey. He constructed his specific naturalism by appropriately merging Darwin's Evolution with a kind of thought of unification that he actively absorbed from American neo-Hegelianism. Though American pragmatism is based on empiricism from European continent, it is quite different from the classical empiricism that was founded by the British giants Francis Bacon, John Lock, George Berkeley and David Hume, and it is also different from the empirical positivism which was primarily popular in England. Evolution is right the secret of Dewey's philosophy which transformed the classical empiricism. While he inherited the pragmatic thoughts from Charles Peirce and William James, Dewey absorbed a lot of thoughts and ideas from Evolution, and with those changing ideas in his mind; he greatly developed, elaborated, and particularly expanded them into various areas including education, democracy politics, moral thought and social construction theory, aesthetics, and so forth. While the traditional philosophical tenets of the so-called second generation empiricism, positivism and logical empiricism, adopt a kind of fixed approach of epistemology, with emphasis on controlled observation and the formal logical structure of our knowledge, Dewey got rid of the idea that regards experience as a sort of dead knowledge or material to be understood, and appealed to Evolution as one foundation to develop a new kind of naturalistic empiricism, which is the real deposit of his constructional pragmatism.

Dewey's metaphysical thought is based on Evolution via the bridge of natural continuity. J. Popp analyzed the idea of genetic determinism briefly to clear up a bias that philosophic analysis of Darwinism necessarily leads to somewhat determinism, and then concluded that Evolution theory could be a foundation for naturalism though it is a science rather than a type of philosophy [2]. According to Popp, although Dewey wrote his first thesis about Evolution theory two and half decades after Darwin published the book, [3] in which Dewey regarded Darwinism as a mightier weapon. Nowadays, DNA (its structure is discovered by F. Crick and J. Watson just one year after Dewey died in 1952) is widely used in the fields of judicatory, medical research and agriculture and so on.

Dewey was the first philosopher who understands that the theory of natural selection would change our thinking about 
ourselves and living forms, and also that approach to philosophy would be changed significantly, because he knew the mind emerging from earlier mindless forms implies new accounts of epistemology or knowledge, ethics and political philosophy; and with that Dewey reconsiders all traditional types of philosophy. Popp mentioned a lot of other writers who paid attention to Darwin's theory but not deeply into its philosophical consequences, such as Cunningham's simple introduction of Dewey, [4] P. Kitcher gives a name of "Naturalist Return" but ignores Dewey's naturalism. [5] As Dennett holds that any adequate account of human capacities must include Evolutionary explanations of how humans came to possess these capacities, [6] Dewey's writings present the development and utilization of naturalized analytical methods to reconstruct the problems and proposed solutions of philosophy. And the recent development in cognitive science supplied evidences for Dewey's arguments, which will likely bring us a new philosophical turn.

Dewey's strong belief on sciences such as Darwinian Evolutionary theory and modern physics drives him to revise a lot of traditional philosophical conceptions, most important ones among which are experience, nature, habit and goodness. The methodology of re-utilization of ordinary words to express new meanings distinguished him from many other philosophers such as M. Heidegger who invented a lot of new words to express his creative philosophical thoughts. Dewey extended Darwinian engineering account by further developing the philosophy of biology, for example, his analysis of continuing "growth" presumably denounced the dual-separations in traditional philosophies.

\section{EVOLUTION IS AN INTELLECTUAL REVOLUTION AS WELL AS A SCIENTIFIC REVOLUTION}

By analyzing the content of Evolution theory and some recent achievements, Dewey's philosophical and educational thoughts about unlearned activities, preparedness and plasticity can be clearly explained. Since Evolution as a science may be examined in every dimension; at the same time, highly concerns of philosophic issues are kept in that theory, as cognitive science is one focus for many of them. We should have a complete understanding of the concept of "natural selection" as it forms the basis of a naturalized approach to knowledge and morality.

In the history of science, Darwin's Evolutionary theory insisting that humans are only modified monkeys has been regarded as a scientific revolution with equal popularity as Copernicus revolution that displaced humans from the center of the universe. The Origin of Species conceals that living things are engaged in a struggle for survival, which means those individuals that possess greater speed, olfaction, sight, agility, claw, fang, and so on have more chances to live than do the other animals with whom they must compete, and they will be more likely to have progeny or to have progeny in greater numbers than those less competitive individuals. By what Darwin calls "natural selection", their species becomes better and better adapted to the environment in which its members must seek to survive. In short, Evolution has three basic requirements: heredity, variation and pressure environment. In another word, heredity can pass stable qualities from one generation to the next, variation within the members of the species in a given environment that are able to replicate themselves under survival pressure, which means that those individuals who possess characteristics that give them a competitive advantage will be more likely selected by means of the competition in a struggle for existence, and competing environment is the selection pressure.

As Dennett pointed out, Darwin discovered an algorithm such that Evolution will occur with any group that has variation, heritability, and is under selection pressure. Mutation seems to be errors, but it is a needed error from the perspective of revolution. Natural selection happens in a random process accepting some variation of characteristics and rejecting others, and there are three kinds of mutation with more mutation stories are being discovered in the research of genetics, $i$. e., famous female sheep Dolly cloned in 1996. The scientific research shows that there are three processes of genetic selection: natural, sexual and methodological or unconscious. For human beings, the vital elements are $\mathrm{X}$ and $\mathrm{Y}$ chromosomes, which are described in more details by Bainbridge.[7] The difference between Lamarckism and Darwinism is pointed out by Dawkins, Lamarckism is nowadays the name given to the theory of Evolution that relies on the assumption that acquired characteristics can be inherited. The significant feature of the Lamarckian theory is the idea that new genetic variation tends to be adaptively directed, rather than "random" (i.e., non-directed) as in the Darwinian Theory. The orthodox view today is that the Lamarckian theory is completely wrong. [8]

Recent work in Evolutionary theory has undermined the usefulness of the distinction of nature and nurture in human development from the perspective of philosophy, a century-old debate, and replaced it with the concepts of "preparedness" and "plasticity", the knowledge of which is required to understand both Evolution and Dewey. Dewey's analysis of innate behaviors, "unlearned activities" as he called, is essential for us to understand all of Dewey's writings. Dennett's thesis about the genetic origins of our impulses shows how the preparedness-plasticity distinction is a replacement for the old and contentious nature-versus-nurture issue. Of particular interest to epistemologists is the discussion in which Kant's synthetic a priori categories are analyzed in terms of the preparedness plasticity distinction, and natural selection.

Various forms of determinism took the place of the genetic form after Darwin: the parental determinism of Freud, the social-economic determinism of Marx, the peer-pressure cultural determinism of Boas and M. Mead; the stimulus-response determinism of Watson and B. Skinner, the linguistic determinism of Sapir and Whorf and so on. However, most recent thinkers take somewhat combined standpoint; Dennett argued that we evolved from the deterministic laws of physical science to the point where we became capable of free choice and taking moral responsibility. [9] Steven Pinker refutes the nurture side of determinism, the blank-slate conception of human learning and behavior. [10] According to Popp, the difficulty with all-nurture explanation is the fact that it must recognize that all animals possess instincts or innate behaviors that are only explained by reference to genomes and the fact that it must 
downplay or reject altogether the idea that humans also have instincts that are more than non-participating carry-overs from our ancient past. In refuting the various forms of determinism, Dewey stands in the side of Russell, but he showed us how to be ultra-naturalists without seeing ourselves as predetermined robots controlled by our genomes.

\section{EVOLUTION'S IMPACT UPON DEWEY'S PHILOSOPHY AND THOUGHTS OF EDUCATION AND DEMOCRACY}

Many of Dewey's philosophical conceptions can be traced back to Darwin's Evolution. Central to Dewey's analysis of reflective thinking and conduct is the notion of habits that are "outgrowths of unlearned activities which are part of man's endowment at birth". [11] But Dewey did not simply deny nature, he preferred the interaction of both, "the meaning of native activities is not native; it is acquired. It depends upon interaction with a matured social medium". According to Dewey, habits are formed under the influence of association with others who already have habits and who show their habits in the treatment which converts a blind physical discharge into a significant anger. Dewey insists that experiences are continuous, so cannot be cut into discreet pieces. In the eye of Popp, the Dewey's educational core concept of Growth, which is elaborated by Evolution theory, encouraging students starting with what is at hand and then going on to change it in ways that satisfy new demands makes Dewey deserve the label "Evolution's first philosopher". Contemporary neuroscience proves the absolute separation of nature and nurture seriously misguided and destructive to understanding human nature and human conduct. The distinction at work today is not nature versus nurture but preparedness versus plasticity. Impulses could be expressed in terms of habits and practices of one's experiences in a specific cultural environment that gives a social context for the habit and its meaning. Genetic explanation is actually the simplest one, and Dewey's thought in his book Human Nature and Conduct is greatly enhanced by the so-called "human genome". He embraced the Darwinian perspective, and held that Darwinian naturalism easily leads to human experience's continuity.

The logical center of Dewey's pragmatism is intellectual growth instead of democracy, because Dewey viewed the Evolution of culture, language, consciousness and intelligence as end indicator, which supersedes others. Ends are not of equal worth, but only growth is special, it is the one with no end beyond itself. As Dewey said, "Nature has no end, no aim, and no purpose. There is change only, not advance towards a goal." [12] By that he means intellectual growth setting in servitude to some other ends will eventually lost its ability in order to adapt itself to new arisen problems. The concept of growth is critical for us to understand Dewey's philosophy, because it is sourced from Evolution, naturalism, and its continuity in a forever-change. In reading Dewey, we shall better to get rid of such idea as the ultimate end of anything (growth is the only exception), essential meaning, perfections, and natural selection does not perfect us as human beings. Popp quotes a pale-ontological assumption of Troodon, a smartest dinosaur, might had been the ruler of the earth in place of Homo sapiens, to argue Evolution is aimless. He maintains "nature has no directions, only consequences", "nature is purely reactive, and never proactive", "our DNA is adaptive". Social Darwinism is not an acceptable solution to the problem of the normative raised by Dawkins “Is Evolution progressive?" Dewey's principle refers to the growth of minds, for example, education is reconstruction or reorganization of experience, which adds to the meaning of experience and increases the ability to control the course of subsequent experience. [13] For Dewey, growth is not value neutral since it rejects the kinds of that are detrimental to an organism.

Evolution shows us that the phenomenon of living things is only adequately explained in terms of the continuity of growth, which is the central characteristic of the theory. Dewey grasped this feature of all living things and saw that any adequate, forward-going analysis of human cognition would have to respect the principle of continuity, which means that mind, consciousness, and knowledge must be described in the same language of constant continuous change required to express the Evolutionary theory. Thus, a hard line between mind and body, or the mental and the physical, is pre-Darwinian. The profoundness of Dewey's understanding of the consequences of Darwin for philosophy can be seen in the current literature in cognitive science, which has subsumed the theory of mind, and denied such a hard distinction between mind and body in favor of talk about the mind-brain or of talk about the mind being something the brain does. Dewey's idea of democratic participation is not a means to any end; instead it is a way of life and the cornerstone of pragmatism. However, Dewey is generally misunderstood in two perceptions: He never says that democracy is the one that validates all other values. At best, democracy and education have an important relationship. The second is that Dewey regard democracy as a political theory that narrows Dewey's conception of democracy. Instead, Dewey maintains that democracy is a reorganization of social experiences, penetrating to all the ways of living, instead only a form of government. [14] The constructional idea of democracy, a kind of growth, combined with education, provides a great and helpful enlightenment to the Chinese modern democratization, for instance, the current village selection broadly carried out in up-to a million of Chinese villages. The classical "reason" is replaced by intelligence in Dewey's terms, which is a matter of effectively organizing one's ends and means. Morality is an important dimension in intellectual growth. With each new development of science and technology, particularly that of genetic applications, a fear rises up in the minds of people that had gone too far and out of control. But the relation between the troubles of AIDS and SARS to science is neglected. The problems of valuation issues arose as products of our emergent intelligence. For Dewey, the only solution to the troubles is to value the use and enhancement of our intelligence. So he thinks that personal development, education, has no end beyond itself. The intellectual growth of every individual is the means to the formation and evaluation of all other means and end problems we confront, and it is a natural process. So Evolution does not have foresight, but it has given foresight to us. However 
philosopher's task is to help improve our cognitive architecture, which Dewey had voluminous writings upon to improve our thinking, and improve the rules that constitute our virtual-computing minds. Dewey refutes any kinds of ideals as ends, and suggests "situational ethics". Therefore his logic is to examine the problem situation for him, and that inquiry leads to so-called "contextual relativism".

Dewey's democratic conception is a kind of socio-cultural ethic well beyond narrow political interpretations that is the usual misunderstanding to his theory, among which $\mathrm{T}$. West's criticism of Dewey is analyzed. Darwinism leads Dewey to reject the conceptions of fixed knowledge and goodness through reason, because the human being emerged from monkey in the natural Evolutional process. He sees the acquisition of knowledge in specifically biological and Evolutionary terms, [15] everything including reason is historical in a progression, not fixed one. So with the society changing, the valuation criteria to judge the goodness is applicable to be different, dependent on the actual context, and the intelligence of human being is capable for that. West's argument "Dewey's liberalism is based on his belief in historical relativity and no permanent human nature" could be deconstructed by Dewey's Human Nature and Conduct, which articulates that our unlearned activities become habits of our conduct in the interaction with those already having such habits, and so does encountered cultures. Dewey also considers religions fictional, and there are no natural standards for its judgment. Dewey's rebuttal to West can be found much earlier in his appeal to the writer of the Declaration of Independence, Thomas Jefferson, in his arguments about the continued intellectual growth at the level of social policy, since West believes Dewey's theory undermined the American Founders including Jefferson.

According to Dewey, democracy is a matter of establishing an ethical "commons" that encourages diversity of expression and divergence of thought. The natural-ethical commons that support Dewey's conception of democracy as a moral form of living supports and encourages individual differences, because growth, as well as both minded and non-minded is sustained by variation. Dewey's analysis of democracy as the moral core of all social intercourse makes plain the conditions under which diversity can flourish without destroying the potential for yet further diversity, and it is significant for the direction of evaluation of our intellectual development and construction of a desirable society.

\section{CONCLUSION}

Dewey began his philosophic career with attention to what Evolutionary theory meant for the development of better methods of philosophic analysis, since Darwinian Evolution and continuity of nature stayed in the center of Dewey's belief for his reconstruction of traditional philosophy. Natural selection has no foresight for any given species let alone all species. But with the emergence of mind or intellectual selection, our species began to develop some abilities to anticipate the consequences of individual actions and, later, of general policies. It should now be clear how Evolutionary theory provides a scientifically created platform upon which one can build a theory of inquiry capable of answering our normative questions. Dewey was the first philosopher to see how Darwin's evolutionary theory created one basis for developing a naturalistic approach for dealing with traditional philosophic problems. While philosophy may appear impotent to some in the face of the problem of the normative on this scale, Dewey's philosophical project was to identify a way of coming at these problems so that the possibility of growth remained viable. Dewey's writings, in their entirety, establish a way of solving or resolving problems so that with each success, we become better and better at dealing with the obstacles to existence.

\section{REFERENCES}

[1] D. John, Middle Works, Carbondale: South Illinois University Press, vol. 4, pp. 14, 1991.

[2] J. A. Popp, Evolution's First Philosopher: D. John and the Continuity of Nature, State University of New York Press, pp. 123, 2007.

[3] D. John, Early Works, Carbondale: South Illinois University Press, vol. 1, pp. 20, 1991.

[4] C. Suzanne, Philosophy and the Darwinism Legacy, New York University of Rochester Press, pp. 123, 1996.

[5] K. Philip, "The Naturalism Return," Philosophic Review, vol. 101, no. 1, 1992.

[6] C. D. Daniel, "The Baldwin Effect: A Crane, Not a Skyhook," Evolution and Learning: The Baldwin Effect Reconsidered Cambridge, MIT Press, pp. 69-79, 2003.

[7] D. Bainbridge, How the X chromosome Controls Our Lives, Cambridge: Harvard University Press, pp. 12, 2003.

[8] R. Dawkins, the Extended Phenotype, Oxford University Press, pp. 23, 1982.

[9] D. Dennett, Freedom Evolves, New York, Viking, pp. 34, 2003

[10] S. Pinker, the Blank Slate: The Modern Denial of Human Nature, pp. 45, 2002.

[11] J. Dewey, Middle Works, Carbondale: South Illinois University Press, vol. 14 , pp. 65,1991

[12] J. Dewey, Early Works, Carbondale: South Illinois University Press, vol. 1, pp. 213, 1991

[13] J. Dewey, Middle Works, Carbondale: South Illinois University Press, vol. 9, pp. 82, 1991.

[14] J. Dewey, Later Works, Carbondale: South Illinois University Press, vol. 12, pp. 31, 1991.

[15] A. O'Hear, Beyond Evolution: Human Nature and the Limits of Evolutionary Explanation, New York: Oxford University Press Inc., pp. 73, 1997.

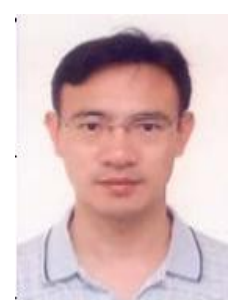

Liu Huachu was born at Xiaogan City of Hubei province, China. Huachu received M.S degree of Engineering Physics from Tsinghua University in 1994, and Ph.D. in Western philosophy from Fudan University in 2010. Huachu workedas a software engineering and manager for more $t$ han ten years in USA, Canada and China since graduation with M.S. and did research in western modern philosophy as a post-doctor in Beijing Normal University after graduation with $\mathrm{PhD}$. He published one book The foundation of Pragmatism: Research on Dewey's Empirical Naturalism and more than 20 papers on western philosophy and Marxism. Now he is working as a professor on social science in the Dept. of Social Science, Hainan Normal University. 